12

\title{
Меры на основе стекол, активированных ионами редкоземельных элементов, для калибровки флуоресцентных и рамановских спектрометров
}

\author{
(С) А.Ю. Садагов ${ }^{1}$, Т.А. Гойдина ${ }^{1}$, В.А. Асеев ${ }^{2}$, Н.В. Никоноров ${ }^{2}$, Ю.К. Федоров ${ }^{2}$, \\ М.М. Чугунова ${ }^{1}$, А.Д. Левин ${ }^{1}$ \\ ${ }^{1}$ Всероссийский научно-исследовательский институт оптико-фризических измерений, \\ 119361 Москва, Россия \\ 2 Университет ИТМО, \\ 197101 Санкт-Петербург, Россия \\ e-mail: levin-ad@vniiofi.ru
}

Поступила в редакцию 29.04.2020 г.

В окончательной редакции 29.04.2020 г.

Принята к публикации 20.05.2020 г.

\begin{abstract}
Представлены результаты разработки мер флуоресценции на основе стекол на фосфатной матрице, активированных ионами редкоземельных металлов. Меры предназначены для спектральной коррекции спектров эмиссии, систематического контроля колебаний чувствительности спектрофлуориметров. Рассмотрена возможность их использования для калибровки спектрометров комбинационного (рамановского) рассеяния.

Ключевые слова: меры флуоресценции, флуоресцирующие стекла, калибровка по спектральной и фотометрической шкалам, спектры возбуждения и эмиссии, фосфатное стекло, ионы европия и тербия, ионы тулия.
\end{abstract}

DOI: $10.21883 /$ OS.2020.10.50028.145-20

\section{Введение}

Флуоресцентные методы все более широко применяются в медико-биологических исследованиях, химии, материаловедении, биохимии. Флуоресцентная спектрофотометрия особенно важна в клинической лабораторной диагностике, фармацевтике, различных биотехнологиях, где требуются измерения малых концентраций аналита $(<1 \mathrm{ppm})$ в пробах малого объема (порядка $\left.1 \mu \mathrm{m}^{3}\right)[1]$. Флуоресцентная микроскопия эффективно используется при исследовании тканей, клеток и других сложных биологических объектов. Среди измерительных задач, возникающих при использовании флуоресцентных методов в указанных областях, можно выделить измерение аппаратно-независимых спектров и квантового выхода флуоресценции.

Спектры возбуждения и эмиссии, измеряемые спектрофлуориметрами, являются аппаратно-зависимыми, т. е. величина сигнала и его форма зависят от прибора, на котором они были измерены. На измеряемый спектр влияют аппаратные функции монохроматоров, интенсивность и спектральная характеристика источника возбуждающего излучения, коэффициенты отражения или пропускания оптических элементов, размеры щелей входного и выходного монохроматоров, спектральная характеристика ФЭУ, особенности позиционирования образца в кюветном отделении (из-за эффекта внутреннего фильтра) и т.д. Вследствие этого для сопоставления результатов, полученных на разных приборах, необходима коррекция измеренных спектров по форме и интенсивности.

Для решения указанных выше задач необходимы стандартные образцы, воспроизводящие спектры флуоресценции по их форме и интенсивности, а также квантовый выход флуоресценции.

Поскольку при качественном и количественном флуоресцентном спектральном анализе используются в основном спектры эмиссии, разработка стандартных образцов, воспроизводящих форму этих спектров, является особенно актуальной.

В качестве стандартных образцов, воспроизводящих спектры эмиссии, хорошо зарекомендовали себя растворы красителей [2,3]. Однако меры на основе жидкостей имеют следующие недостатки.

1. Недостаточная стабильность из-за возможности химических и фотохимических реакций в растворе.

2. Необходимость хранения при пониженных температурах.

3. В большинстве случаев жидкие стандартные образцы не рассчитаны на непосредственное использование, а требуют приготовления рабочих растворов с очень ограниченным сроком годности. Вследствие этого использовать их для систематического контроля чувствительности прибора невозможно.

В связи с отмеченными выше недостатками жидких стандартных образцов предпринимались попытки создания стандартных образцов флуоресценции (СОФ) на основе твердых материалов. Наиболее простым способом обеспечения требуемых спектров флуоресценции явля- 
ется введение соответствующих добавок в прозрачные полимеры. Наиболее подходящим для этих целей полимерным материалом является полиметилметакрилат (ПММА, органическое стекло), который прозрачен в широкой области спектра и имеет высокую оптическую однородность. На основе ПММА выпускается, например, набор стандартных образцов для молекулярной спектрофлуориметрии [4].

Флуоресцентные красители, входящие в состав стандартных образцов на основе полимеров, подвержены фотохимической деградации, хотя и в меньшей степени, чем в образцах на основе жидкостей. Особенно существенной становится такая деградация под воздействием УФ излучения. Еще один существенный недостаток таких стандартных образцов заключается в высокой анизотропии флуоресценции.

В последние несколько лет стали появляться меры на основе неорганических стекол. Преимуществами таких стандартных образцов перед твердыми образцами на основе полимеров являются

1) малая анизотропия флуоресценции,

2) отсутствие зависимости флуоресцентных свойств от температуры,

3) устойчивость к тепловым, химическим и фотохимическим воздействиям.

В течение 2008-2013 гг. NIST были разработаны стандартные образцы на основе неорганических стекол [5-9], предназначенные для коррекции относительных спектров эмиссии. Каждый из этих стандартных образцов имеет достаточно широкую линию эмиссии, а в совокупности они охватывают достаточно широкий диапазон длин волн эмиссии - от 320 до $630 \mathrm{~nm}$. Эти стандартные образцы выполняют две основные функции - относительная коррекция спектров эмиссии и ежедневный контроль стабильности чувствительности спектрофлуориметров.

В 2015 г. Федеральным институтом по исследованиям и испытаниям материалов ФРГ (ВАМ) был разработан стандартный образец для флуорометрии из лантанофосфатного стекла, легированного ионами нескольких редкоземельных металлов и имеющего несколько узких линий в спектре эмиссии в диапазоне от 450 до $750 \mathrm{~nm}$ [10]. Наряду с функциями, выполнявшимися стандартными образцами NIST (National Institute of Standards and Technology, USA), данный образец может также использоваться для контроля погрешности эмиссионного канала флуориметра по шкале длин волн.

В настоящей работе приводятся результаты разработки мер на основе неорганических стекол с несколькими узкими линиями флуоресценции. При этом стояла цель как расширить спектральный диапазон, охватываемый этими мерами, так и обеспечить для них дополнительные функции по обеспечению единства измерений в флуорометрии.

Описаны процедуры синтеза специальных стекол, активированных ионами редкоземельных металлов, исследованы оптические, прежде всего флуоресцентные свойства стекол и стабильность этих свойств в реальных условиях эксплуатации мер.

Рассмотрены различные возможности применения разработанных мер. Наряду с известными ранее приложениями для подобных мер, которые были рассмотрены выше, предлагается несколько новых, таких как калибровка спектрофлуориметров в относительных единицах флуоресценции, относительные измерения квантового выхода флуоресценции, использование мер для калибровки спектрометров комбинационного рассеяния (КР, рамановских) по спектральной и фотометрической шкалам.

\section{Синтез стекол с заданными флуоресцентными свойствами}

Для решения вышепоставленных задач были разработаны два специальных флуоресцентных стекла на основе фосфатной матрицы. Одно из стекол было активировано ионами европия и тербия, а другое - ионами тулия. Состав матрицы каждого из стекол представлял собой смесь метафосфатов элементов II-III групп и лантана. Активация редкоземельными ионами обеспечивалась эквимолекулярной заменой в составе стекла оксида лантана либо на оксиды европия и тербия, либо на оксид тулия, в обоих случаях достигалась однородность активаторных центров. Разработанные стекла имеют низкую кристаллизационную способность в интервале температур $700-1100^{\circ} \mathrm{C}$, высокую химическую устойчивость к действию влажной атмосферы, высокую фотохимическую устойчивость и термостойкость.

В лабораторных условиях стекла варили из смеси сухих метафосфатов элементов II группы $(\mathrm{Ca}, \mathrm{Sr}, \mathrm{Ba}$, $\mathrm{Pb}$ ), алюминия и лантана, оксидов европия, тербия и тулия. Использовались реактивы высших квалификаций по чистоте - не хуже „х.ч.“. Варки вели из расчета на $150-200 \mathrm{~g}$ стекла в стекритовых $\left(\mathrm{SiO}_{2}\right)$ тиглях с перемешиванием платиновой мешалкой в течение $2-3 \mathrm{~h}$ (частота вращения $n \sim 60 \mathrm{rpm}$ ) при $1250^{\circ} \mathrm{C}$. Расплав отливали при $1000-1050^{\circ} \mathrm{C}$ в подогретые графитовые формы и отжигали при $520^{\circ} \mathrm{C}$ в течение $1 \mathrm{~h}$. Полученные заготовки визуально просматривали на однородность и пузырчатость. Из однородных участков этих заготовок изготавливали образцы мер, размеры которых соответствовали внешним габаритам стандартной флуорометрической кюветы $(12.5 \times 12.5 \times 45 \mathrm{~mm})$, все четыре боковые грани были прозрачными.

\section{Применяемая аппаратура и материалы}

Исследования оптических свойств мер, включая их спектры флуоресценции, проводились на спектрофотометре-флуориметре СФФ-2, „Флуоран“ (разработка ФГУП „ВНИИОФИ“) Для отработки методики калибровки спектрометров КР использовался раманлюминесцентный спектрометр „ИнСпектр R 532“, раз- 
работанный ООО „ИнСпектр“ (Российская научнопроизводственная компания при Институте физики твердого тела РАН).

Меры на основе ионов тербия и европия были откалиброваны в относительных единицах флуоресценции $(\mathrm{OЕФ).} \mathrm{Для} \mathrm{калибровки} \mathrm{мер} \mathrm{в} \mathrm{ОЕФ} \mathrm{применялся}$ Комплект мер флуоресценции КМФ на основе растворов флуоресцеина натрия различных концентраций, выпускаемый ФГУП „ВНИИОФИ,. Измерения проводились на люминесцентном комплексе государственного первичного эталона ГЭТ 196-2015, основу которого составляет спектрофлуориметр Fluorolog-3-22 („HORIBA Jobin Yvon S.A.S“, Франция).

\section{Исследованием оптических свойств мep}

Исследования проводились с целью установления оптических (метрологических) характеристик мер флуоресценции: спектрального диапазона, диапазона воспро-

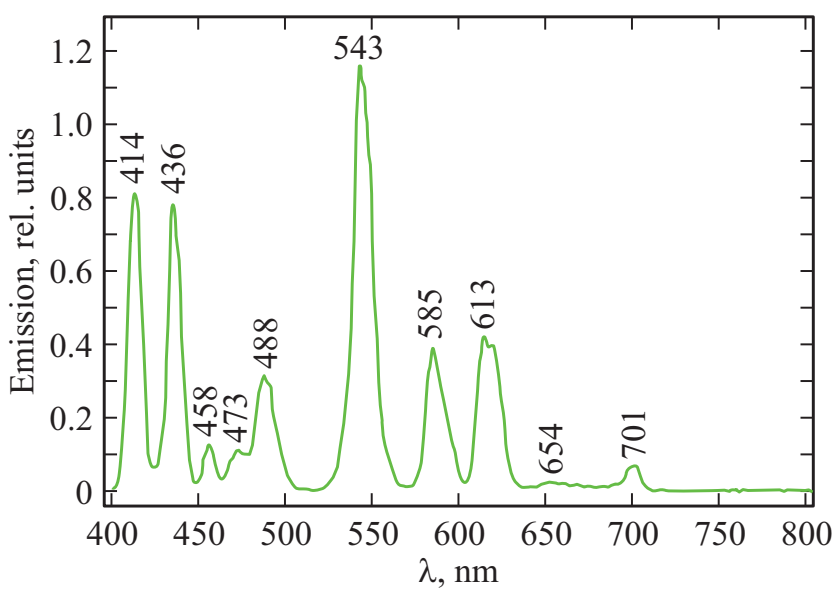

Pис. 1. Спектр эмиссии для мер флуоресценции на основе фосфатного стекла, активированного ионами европия и тербия.

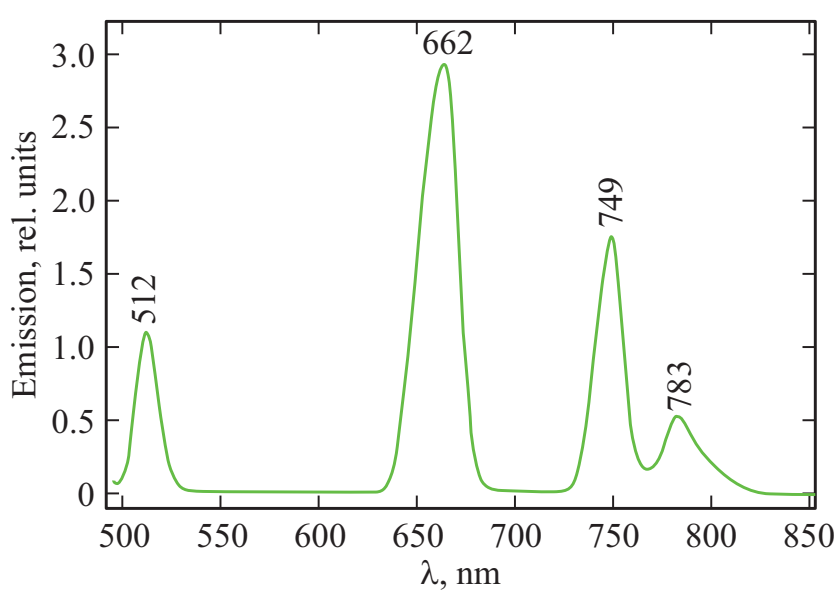

Рис. 2. Спектр эмиссии для мер флуоресценции на основе фосфатного стекла, активированного ионами тулия.
Таблица 1. Относительные интенсивности пиков мер флуоресценции

\begin{tabular}{l|c|c}
\hline \multicolumn{1}{c|}{ Основа } & Длина волны, nm & $\begin{array}{c}\text { Относительная } \\
\text { интенсивность }\end{array}$ \\
\hline На основе & 414 & 0.71 \\
европия & 436 & 0.38 \\
и тербия & 458 & 0.1 \\
& 488 & 0.27 \\
& 543 & 1 \\
& 585 & 0.34 \\
& 613 & 0.38 \\
На основе & 701 & 0.07 \\
тулия & 512 & 0.38 \\
& 662 & 1 \\
& 749 & 0.6 \\
& 783 & 0.17
\end{tabular}

изведения ими спектральной эффективности флуоресценции, выяснения основных источников неопределенности такого воспроизведения, а также различия свойств между мерами одного и того же типа.

\section{Исследование спектров флуоресценции и их зависимости от длины волны возбуждения}

Спектр эмиссии меры на основе стекла, активированного ионами европия и тербия, приведен на рис. 1 , а меры на основе стекла, активированного ионами тулия, - на рис. 2.

Спектр флуоресценции мер на основе тербия и европия содержит восемь достаточно узких и чётких спектральных линий в диапазоне $400-730 \mathrm{~nm}$ при длине волны возбуждения $365 \mathrm{~nm}$, являющейся для них оптимальной. Спектр мер на основе тулия, в свою очередь, содержит четыре линии в диапазоне $500-850 \mathrm{~nm}$ при длине волны возбуждения $358 \mathrm{~nm}$, являющейся для них оптимальной. Данные об относительной интенсивности пиков приведены в табл. 1.

Таким образом, в совокупности обе меры поддерживают воспроизведение спектров эмиссии в достаточно широком диапазоне длин волн, в котором флуоресцируют многие соединения.

Исследование зависимости спектров эмиссии флуоресценции от длины волны возбуждения представляет интерес, поскольку даже небольшое изменение длины волны возбуждения, вызванное, например, погрешностью монохроматора канала возбуждения, может быть одним из источников неопределенности при воспроизведении мерами спектров эмиссии. Для флуоресцентных красителей, растворенных в жидкостях, хорошо выполняется эмпирическое правило Каша, согласно которому форма спектров эмиссии не зависит от длины волны возбуждения при ее изменении в небольших пределах [11]. Это правило хорошо выполняется для люминесценции 


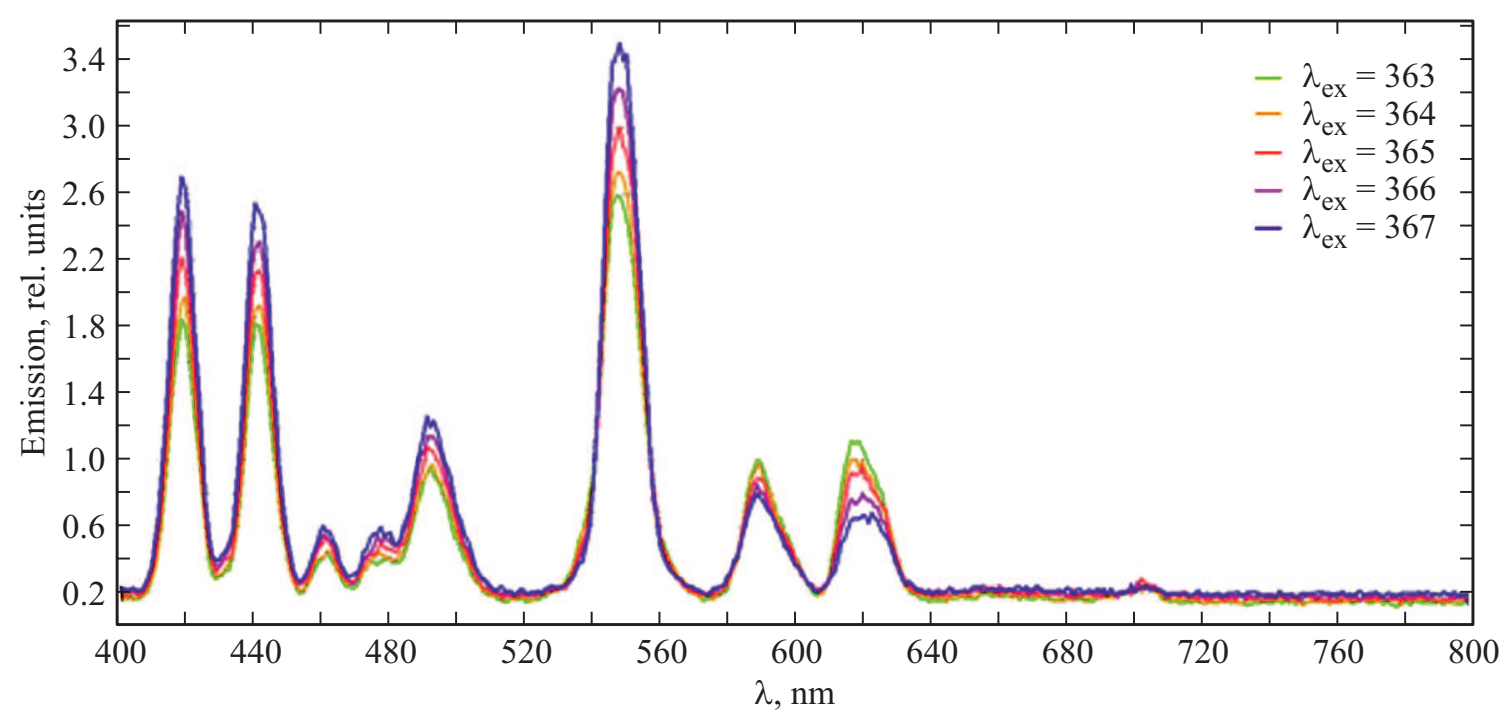

Рис. 3. Спектры эмиссии меры при различных длинах волн возбуждения в интервале от 363 до $367 \mathrm{~nm}$.

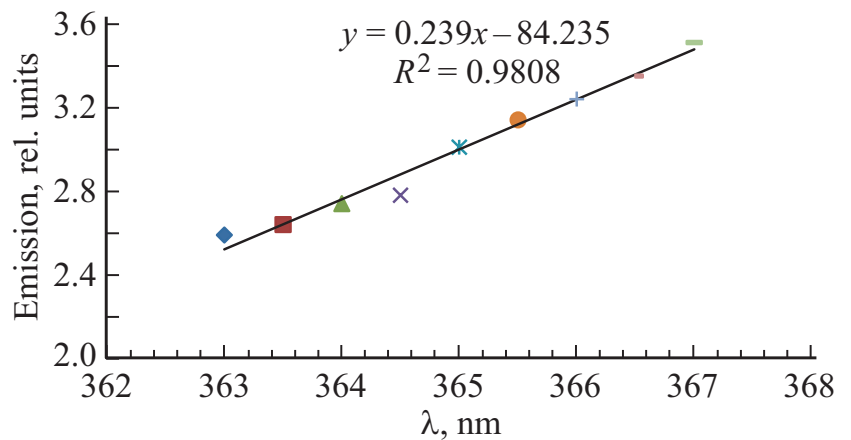

Рис. 4. Зависимости интенсивности флуоресценции в максимуме пика с максимальной интенсивностью $(\lambda=548 \mathrm{~nm})$ от длины волны возбуждения.

молекул в растворе, однако в случае мер на основе стекол, где имеет место флуоресценция внедренных ионов редкоземельных металлов, от него возможны отклонения. В связи с этим нельзя исключать составляющую неопределенности при воспроизведении мерой формы спектров эмиссии за счет неточности установки длины волны в канале возбуждения спектрофлуориметра.

На интенсивность эмиссии изменение длины волны возбуждения может оказывать более значительное влияние, чем на форму. Для оценки указанных выше эффектов были проведены исследования зависимости спектров эмиссии мер от длины волны возбуждения.

На рис. 3 приведены результаты измерения спектров эмиссии для одной из мер при варьировании длины волны возбуждения в интервале от 363 до $367 \mathrm{~nm}$. Из этих данных видно, что для этого стекла также хорошо выполняется правило Каша, т. е. форма спектра не меняется при изменении длины волны возбуждения.

Была измерена зависимость интенсивности флуоресценции в максимуме одного из пиков эмиссии $(548 \mathrm{~nm})$ от длины волны возбуждения. Результаты приведены на рис. 4. Видно, что интенсивность флуоресценции линейно возрастает с увеличением длины волны возбуждения во всем исследовательском диапазоне от 363 до $368 \mathrm{~nm}$. Оцененное по этим данным относительное изменение интенсивности флуоресценции составляет $\sim 6 \%$ при сдвиге длины волны возбуждения на $1 \mathrm{~nm}$.

В реальных рабочих спектрофлуориметрах предел допускаемой погрешности установки длины волны не превышает $0.5 \mathrm{~nm}$. Следовательно, составляющая неопределенности, обусловленная неточной установкой длины волны при воспроизведении интенсивности (спектральной эффективности) флуоресценции, не будет превышать $3 \%$ для исследуемых мер.

\section{Исследование оптической однородности мер}

Оптическая однородность мер является существенным показателем их качества, поскольку она определяет, насколько будет зависеть интенсивность флуоресценции от положения меры в кюветном отделении спектрофлуориметра.

В связи с этим для каждой из изготовленных мер была исследована интенсивность флуоресценции при 8 различных положениях в кюветном отделении, отличающихся друг от друга поворотом на $90^{\circ}$ в горизонтальной плоскости и на $180^{\circ}$ в вертикальной плоскости. Полученные при этом результаты для мер на основе тербия и европия приведены на рис. 5, $a$, а для мер на основе тулия - на рис. $5, b$.

Для данных типов мер характерна высокая изотропия, что должно существенно облегчить их использование при воспроизведении спектров флуоресценции. Более подробные исследования однородности, проведенные путем сравнения интенсивностей в максимумах других пиков, показали, что размах (разница между максимальным 

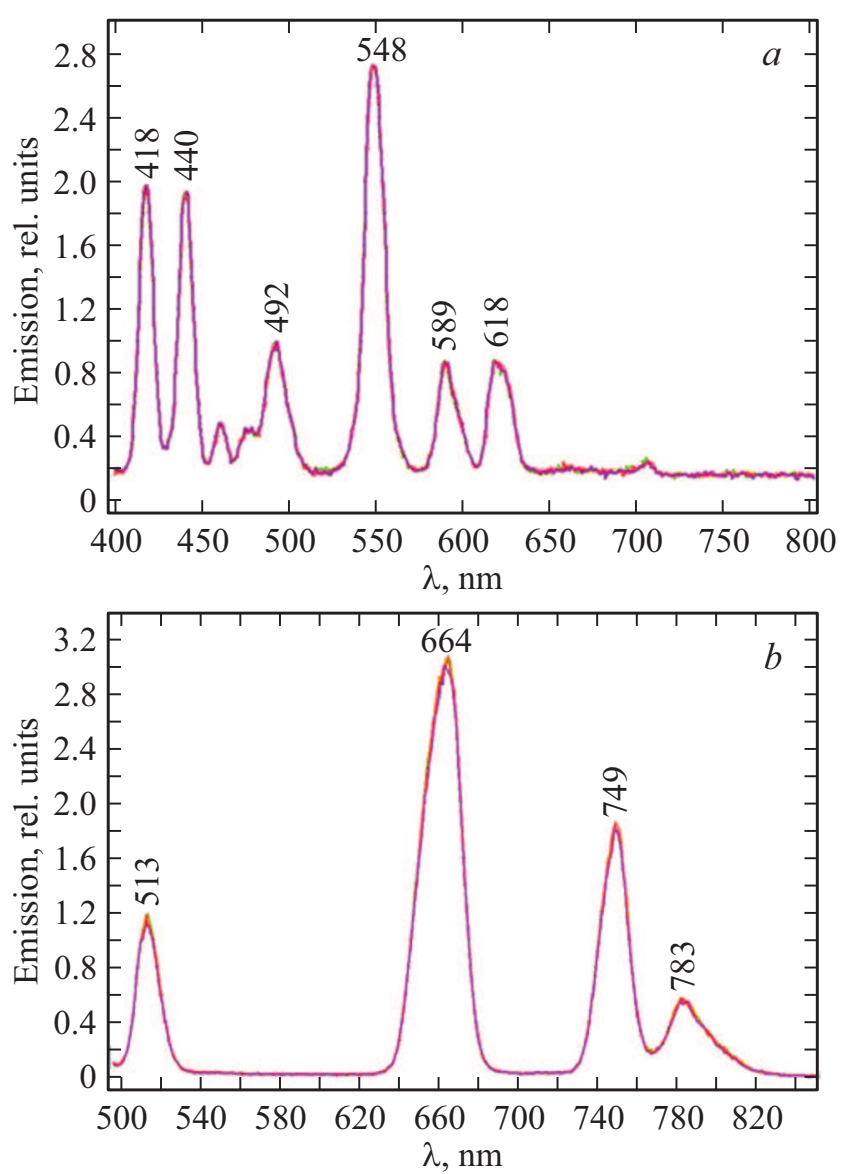

Рис. 5. Интенсивность флуоресценции при 4 различных положениях мер в кюветном отделении спектрофлуориметра, отличающихся друг от друга поворотом на $90^{\circ}(a)$ для мер на основе европия и тербия и $(b)$ для мер на основе тулия.

Таблица 2. Результаты калибровки меры флуоресценции в ОЕФ при длине волны возбуждения $405 \mathrm{~nm}$ и спектральной ширине щели $2 \mathrm{~nm}$

\begin{tabular}{c|c|c}
\hline $\begin{array}{c}\text { Положение пика } \\
\text { эмиссии, nm }\end{array}$ & $\begin{array}{c}\text { Интенсивность } \\
\text { флуоресценции, } \\
\text { rel. units }\end{array}$ & $\begin{array}{c}\text { Погрешность } \\
\text { измерения, \% }\end{array}$ \\
\hline 592 & 1.09 & 2 \\
612 & 3.93 & 2 \\
701 & 1.36 & 3 \\
\hline
\end{tabular}

и минимальным значениями) интенсивностей, обусловленный различиями в ориентации, не превышает $3 \%$.

\section{Калибровка мер в относительных единицах флуоресценции}

Интенсивность эмиссии флуоресценции, измеряемая обычным спектрофлуориметром, зависит не только от свойств анализируемого образца, но и от ряда характеристик прибора, в частности от интенсивности и спектрального состава излучения лампы, спектральных функций пропускания монохроматоров и других оптических элементов, спектральной чувствительности фотоприемников. Для сопоставления результатов измерений, проведенных на разных приборах, особенно в случае биомедицинских приложений, выражают результаты измерений в так называемых относительных единицах флуоресценции - ОЕФ (в англоязычной литературе relative fluorescence units - RFU). За одну ОЕФ принимается интенсивность эмиссии определенного флуоресцентного красителя при заданных значениях его концентрации, длин волн возбуждения и эмиссии. Часто в этих целях используется флуоресцеин натрия (один из наиболее востребованных и эффективных флуоресцентных красителей) при концентрации $1 \mathrm{mg} / \mathrm{dm}^{3}$. Для воспроизведения ОЕФ ФГУП „ВНИИОФИ“ выпускает Комплект мер флуоресценции КМФ на основе растворов флуоресцеина натрия различных концентраций.

Измерения были произведены на люминесцентном комплексе государственного первичного эталона ГЭТ 196-2015, предварительно откалиброванном с помощью комплекта КМФ. Для калибровки были выбраны три наиболее интенсивных пика меры на основе европия и тулия. Соответствующий фрагмент спектра представлен на рис. 6.

Результаты калибровки меры в ОЕФ представлены в табл. 2.

При более коротковолновом возбуждении (381 и $365 \mathrm{~nm}$ ) интенсивность флуоресценции существенно возрастает, поэтому измерения проводились при спектральной ширине щелей возбуждения и эмиссии по $1 \mathrm{~nm}$.

Спектры эмиссии мер при различных длинах волн возбуждения приведены на рис. 7 .

Как видно из рис. 6, 7, при длине волны возбуждения $405 \mathrm{~nm}$ спектральная эффективность флуоресценции сравнительно невелика, полосы эмиссии в районе $489 \mathrm{~nm}$

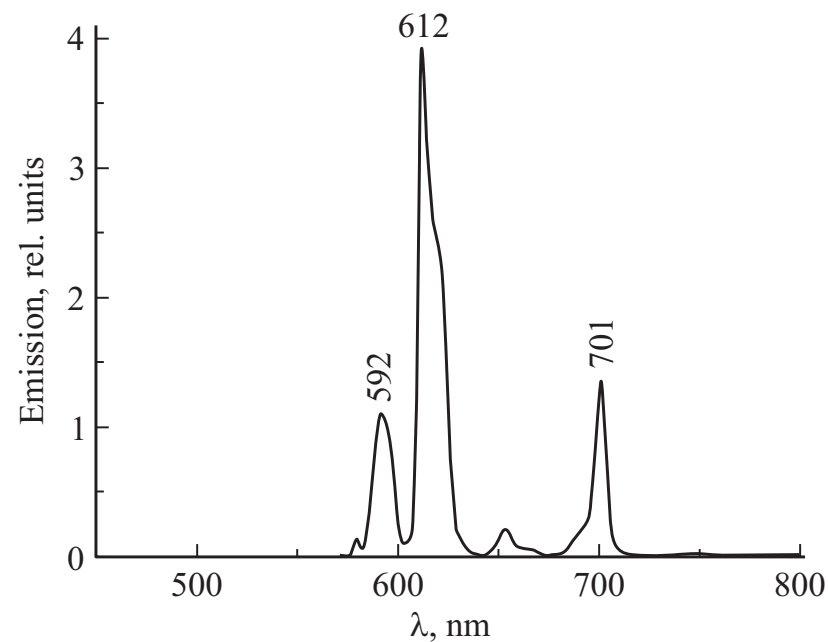

Рис. 6. Фрагмент спектра меры на основе тербия и европия. Измерения проведены на люминесцентном комплексе ГЭТ 196-2015. Длина волны возбуждения $405 \mathrm{~nm}$, спектральная ширина щели $2 \mathrm{~nm}$. 


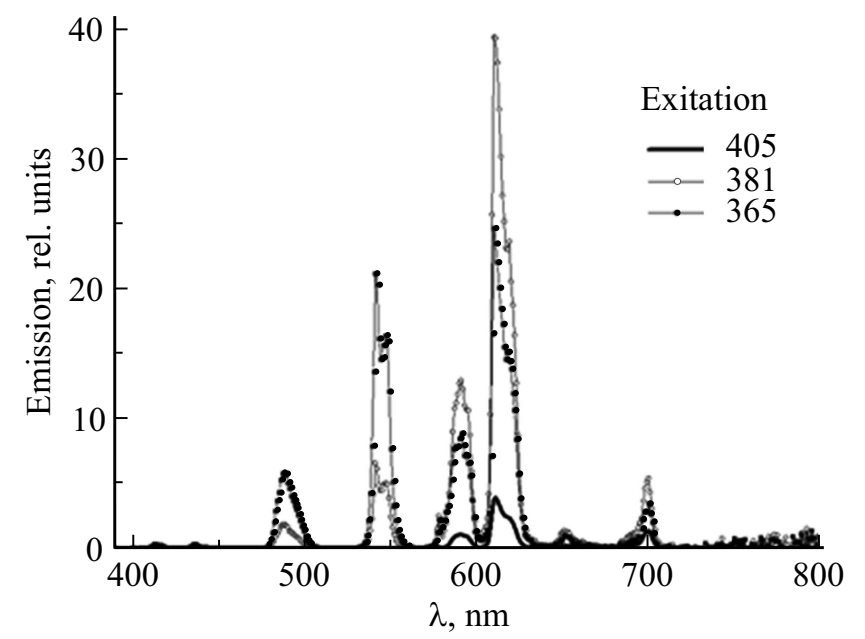

Pис. 7. Спектры эмиссии мер флуоресценции при различных длинах волн возбуждения; на оси ординат приведена интенсивность, выраженная в ОЕФ.

и 540-550 nm не возбуждаются. При уменьшении длины волны возбуждения до $381 \mathrm{~nm}$ видны уже все полосы, но эффективность флуоресценции, обусловленная вероятностью излучательных переходов, заметно увеличивается в сторону меньших энергий (т.е. больших длин волн). При ещё большей энергии возбуждения (длина волны $365 \mathrm{~nm}$ ) интенсивность пиков становится более равномерной.

\section{Исследование зависимости спектров флуоресценции мер от температуры}

Исследование зависимости спектров флуоресценции от температуры также проводилось на люминесцентном комплексе эталона ГЭТ 196-15. Измерения проводились в интервале температур от $+15^{\circ} \mathrm{C}$ до $+35^{\circ} \mathrm{C}$.

Исследование температурной зависимости было проведено на длине волны $489 \mathrm{~nm}$ при возбуждении на $365 \mathrm{~nm}$ при спектральных ширинах щелей $1 \mathrm{~nm}$. Результаты приведены в табл. 3.

Из данных табл. 3 можно сделать вывод, что для указанной полосы наблюдается классическое температурное тушение флуоресценции. При этом изменение интенсивности флуоресценции в диапазоне температур от $+15^{\circ} \mathrm{C}$ до $+35^{\circ} \mathrm{C}$ не превышает $10 \%$. Аналогичные результаты были получены для остальных полос в спектре эмиссии при той же длине волны возбуждения.

Во всех современных спектрофлуориметрах имеются термостаты, обеспечивающие поддержание заданной температуры в кюветном отделении. Отклонение заданной температуры от фактической даже для самых простых и бюджетных приборов не может превышать $\pm 1^{\circ} \mathrm{C}$. Исходя из этого и используя приведенные выше экспериментальные данные, можно оценить составляющую неопределенности, обусловленную температурной
Таблица 3. Температурная зависимость интенсивности флуоресценции для полосы эмиссии $489 \mathrm{~nm}$

\begin{tabular}{c|c}
\hline $\begin{array}{c}\text { Температура } \\
\text { образца, }{ }^{\circ} \mathrm{C}\end{array}$ & $\begin{array}{c}\text { Интенсивность } \\
\text { флуоресценции, rel. units }\end{array}$ \\
\hline 15 & 6.12 \\
22 & 5.85 \\
35 & 5.66
\end{tabular}

Таблица 4. Вклад различных составляющих в неопределенность воспроизведения интенсивности (спектральной эффективности) флуоресценции мерами

\begin{tabular}{c|c|c|c}
\hline № п. п. & Обозначение & $\begin{array}{c}\text { Составляющая } \\
\text { неопределенности }\end{array}$ & Значение \\
\hline 1 & $\Delta \sigma_{\text {heterog }}$ & $\begin{array}{c}\text { Оптическая } \\
\text { неоднородность } \\
\text { меры }\end{array}$ & $\begin{array}{c}\sim 1.5 \% \text { при } \\
\text { произвольной } \\
\text { установке }\end{array}$ \\
\hline 2 & $\sigma_{\lambda}$ & $\begin{array}{c}\text { Зависимость } \\
\text { флуоресценции } \\
\text { от длины волны } \\
\text { возбуждения }\end{array}$ & $\begin{array}{c} \pm 3 \% \text { на } 0.5 \mathrm{~nm} \\
\text { сдвига } \\
\text { монохроматора }\end{array}$ \\
\hline 3 & $\sigma_{T}$ & $\begin{array}{c}\text { Зависимость } \\
\text { флуоресценции } \\
\text { от температуры }\end{array}$ & $1 \%$ на $1^{\circ} \mathrm{C}$ \\
\hline 4 & $\sigma_{\text {instab }}$ & $\begin{array}{c}\text { Нестабильность } \\
\text { флуоресцентных } \\
\text { свойств стекла }\end{array}$ & $<5 \%$ \\
\hline 5 & $\Delta$ & $\begin{array}{c}\text { Суммарная } \\
\text { стандартная } \\
\text { неопределенность }\end{array}$ & $<6.1 \%$ \\
\hline
\end{tabular}

зависимостью интенсивности флуоресценции как $\pm 1 \%$ для исследуемых мер.

\section{Метрологические характеристики мер}

Экспериментальные исследования, результаты которых изложены выше, позволили оценить вклад различных составляющих в неопределенность воспроизведения разработанными мерами интенсивности флуоресценции. Результаты этих оценок приведены в табл. 4.

Суммарная неопределенность $\Delta$ оценивалась по формуле

$$
\Delta=\sqrt{\delta_{\text {heterog }}^{2}+\sigma_{\lambda}^{2}+\sigma_{t}^{2}+\sigma_{\text {instab }}^{2}} .
$$

\section{Спектры флуоресценции мер, измеренные на КР-спектрометре при возбуждении лазером на длине волны $532 \mathrm{~nm}$}

Все более широкое применение спектроскопии КР (рамановской) для качественного и количественного 


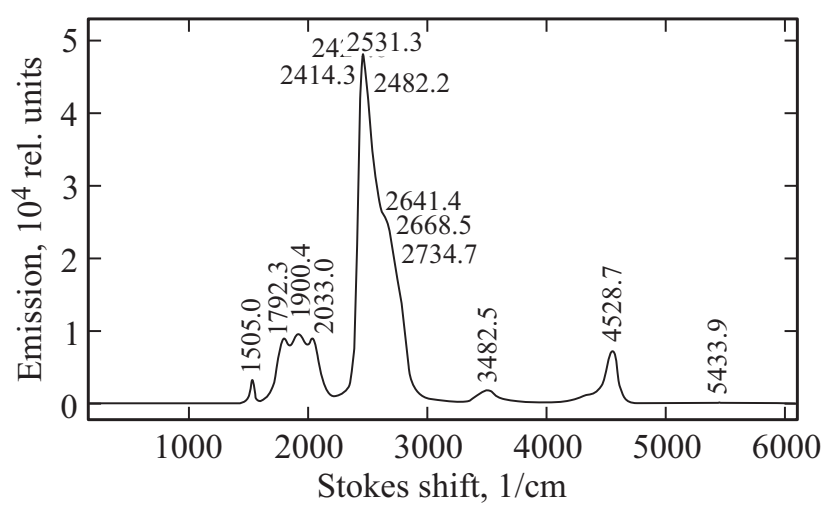

Pис. 8. Спектры флуоресценции в шкале стоксовых сдвигов меры на основе фосфатного стекла, активированного ионами тербия.

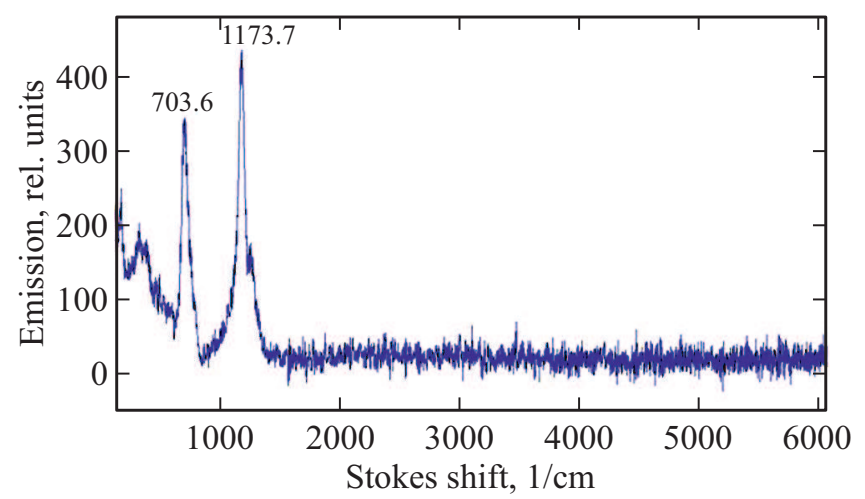

Рис. 9. Спектры флуоресценции в шкале стоксовых сдвигов для меры на основе фосфатного стекла, активированного ионами тулия.

анализа веществ и материалов требует измерения точных и аппаратно-независимых КР-спектров. Это особенно необходимо при распознавании веществ путем сравнения экспериментальных КР-спектров с библиотечными. В этом случае приходится, естественно, сравнивать спектры, измеренные на разных приборах. Для обеспечения аппаратной независимости спектров КР необходимо решение двух задач.

1) Калибровка спектрометра КР по шкале волновых чисел, которая обычно осуществляется либо с помощью внешних источников света, например газоразрядных ламп, либо с помощью образцов с известными значениями волновых чисел рамановских пиков. Недостаток первого способа заключается в сложности обеспечения для внешнего источника света того же положения и такой же диаграммы направленности, что и для исследуемого образца. В качестве образцов с известными положениями рамановских сдвигов обычно используются либо растворы органических жидкостей, либо твердые полимерные образцы (полистирол) [12].

2) Калибровка спектрометров КР по форме спектров, т. е. по относительным интенсивностям рамановских пи- ков, в ряде случаев осуществляется с помощью калиброванных ламп белого света. В 2007 г. для этих целей были разработаны стандартные образцы NIST на основе стекол, имеющих одну широкую линию флуоресценции. Использование таких образцов существенно упрощает процедуру калибровки и делает ее более точной [13]. К специальным стеклам для подобных образцов NIST предьявляет следующие требования: а) достаточно интенсивная флуоресценция под действием лазерного излучения, возбуждающего КР, обеспечивающая стоксовые сдвига в диапазоне волновых чисел от 200 до $4000 \mathrm{~cm}^{-1}$, б) фотостабильность, в) малое поглощение на длине волны возбуждающего излучения, необходимое для предотвращения нагрева под воздействием излучения лазера.

Была исследована возможность использования разработанных мер флуоресценции для решения обеих названных выше задач. Для этого на спектрометре КР „ИнСпектр R 532“, в котором спектры КР возбуждаются с помощью лазера на длине волны $532 \mathrm{~nm}$, были зарегистрированы спектры флуоресценции обеих мер, рассматриваемых в рамках данной работы. Результаты в шкале волновых чисел приведены на рис. 8 и 9. Хотя эти меры наиболее эффективно возбуждаются в более коротковолновой области, однако на длине волны $532 \mathrm{~nm}$ наблюдается достаточно сильная флуоресценция, особенно у мер на основе тербия и европия.

Приведенные спектры показывают, что в совокупности меры воспроизводят пики в диапазоне от 200 до $4700 \mathrm{~cm}^{-1}$, т.е. в области, где наблюдаются рамановские сдвиги большинства представляющих интерес веществ. Оба вида мер имеют достаточно слабое поглощение на длине волны возбуждающего лазера - оптическая плотность на длине волны $532 \mathrm{~nm}$ для мер на основе европия и тербия составляет $0.082 \mathrm{~B}$, а для мер на основе тулия 0.045 В. Многократные измерения, проведенные с мерами обоих типов, показали, что интенсивность всех зарегистрированных пиков остается неизменной. Это свидетельствует о фотостабильности мер при воздействии лазерного излучения, используемого для регистрации спектров КР. Приведенные результаты свидетельствуют о возможности использования разработанных мер также для калибровки спектрометров КР как по шкале волновых чисел, так и по форме спектров, т.е. по относительной спектральной чувствительности.

\section{Применение мер}

\section{Использование мер для измерения аппаратно-независимых спектров эмиссии}

Для каждой из мер необходимо наличие эталонного (паспортного) аппаратно-независимого спектра эмиссии $F_{\text {меры_этал. }}(\lambda)$. Такой спектр должен быть измерен на флуорометрической установке, спектральная чувствительность эмиссионного канала которой прослеживается к первичному радиометрическому эталону. 
Для построения функции спектральной коррекции конкретного спектрофлуориметра необходимо измерить на нем спектр эмиссии используемой меры $F_{\text {меры_изм. }}\left(\lambda_{i}\right)$. Функции спектральной коррекции $\operatorname{Corr}\left(\lambda_{i}\right)$ для значений $\lambda_{i}$, соответствующих максимумам спектральных линий, вычисляются по формуле

$$
\operatorname{Cor}\left(\lambda_{i}\right)=\frac{F_{\text {меры_изм. }} \lambda_{i}}{F_{\text {меры_этал. }}\left(\lambda_{i}\right)} .
$$

По полученным значениям в шести указанных точках зависимость $\operatorname{Corr}\left(\lambda_{i}\right)$ аппроксимируется полиномом третьей степени. Подбор коэффициентов полинома производится методом наименьших квадратов.

Скорректированный (аппаратно-независимый) спектр эмиссии измеряемого образца $F_{\text {обр_корр }}(\lambda)$ вычисляется по формуле

$$
F_{\text {обр_корр }}(\lambda)=\frac{F_{\text {обр_изм. }} \lambda}{\operatorname{Cor}(\lambda)} \text {. }
$$

Рекомендуется определенную для данного спектрофлуориметра функцию спектральной коррекции сохранять в его компьютерной программе, чтобы в дальнейшем при измерении каждого образца вычислялся его аппаратно-независимый спектр по формуле (3). Такой же подход может быть использован при калибровке спектрометров КР (рамановских) по относительной спектральной чувствительности.

\section{Использование мер для учета и компенсации измерений чувствительности эмиссионного канала спектрофлуориметра}

В процессе эксплуатации спектрофлуориметров возможны колебания чувствительности за счет изменения интенсивности свечения лампы, коэффициентов пропускания, чувствительности фотоприемника (ФЭУ) и от отражения оптических элементов. Колебания за счет изменений в канале возбуждения (в первую очередь за счет лампы) компенсируются только при наличии опорного канала. Колебания чувствительности эмиссионного канала самим спектрофлуориметром не компенсируются и являются одним из источников погрешности, особенно при количественном химическом анализе с использованием ранее построенных градуировочных графиков.

Для учета и компенсации подобных колебаний существует процедура систематического контроля чувствительности с помощью мер. Она заключается в измерении и записи в программное обеспечение спектрофлуориметра опорного (референтного) значения интенсивности флуоресценции при заданных параметрах измерения (длина волны, спектральная ширина щели, усиление) -

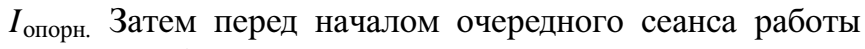
со спектрофлуориметром измеряется значение сигнала при тех же условиях $I_{\text {текущ }}$ и вычисляется коэффициент коррекции $K$ по формуле

$$
K=\frac{I_{\text {опорн }}}{I_{\text {текущ }}} .
$$

После этого каждое измеренное в текущем сеансе значение интенсивности флуоресценции умножается на коэффициент коррекции.

\section{Использование мер для контроля погрешности спектрофлуориметра по шкале длин волн}

Разработанные меры могут быть также использованы для проверки погрешности спектрофлуориметра по шкале длин волн. Для этого производится сравнение положения зарегистрированных на контролируемом приборе пиков эмиссии с положением пиков на паспортном спектре. Таким образом, возможно осуществлять контроль параметров эмиссионного канала спектрофлуориметра.

\section{Заключение}

Разработаны два вида меры флуоресценции на основе фосфатных стекол, активированных ионами редкоземельных металлов - тербием, европием и тулием. Спектр эмиссии разработанных мер охватывает достаточно широкий диапазон длин волн - от 400 до $850 \mathrm{~nm}$ и содержит в совокупности 12 узких пиков (8 у мер на основе европия и тербия и 4 у мер на основе тулия). Исследованы оптические свойства мер, влияющие на их метрологические характеристики, в том числе оптическая однородность, зависимость эмиссии от длины волны возбуждения и температуры, фотостабильность. Разработанные меры могут быть использованы для решения следующих задач:

1) коррекции относительной спектральной чувствительности эмиссионных каналов спектрофлуориметров с целью получения аппаратно-независимых спектров;

2) систематического контроля стабильности чувствительности спектрофлуориметров;

3) проверки погрешности эмиссионного канала спектрофлуориметра по шкале длин волн.

Показана возможность использования разработанных мер для калибровки спектрометров КР по относительной спектральной чувствительности и шкале волновых чисел в диапазоне от 200 до $4700 \mathrm{~cm}^{-1}$.

Предполагается, что разработанные меры позволят обеспечить измерение аппаратно-независимых спектров флуоресценции и КР.

\section{Финансирование работы}

Работа выполнена с использованием оборудования ЦКП высокоточных измерительных технологий в области фотоники (ckp.vniiofi.ru), созданного на базе ФГУП „Всероссийский научно-исследовательский институт оптико-физических измерений“ и финансово поддержанного Министерством науки и высшего образования России в рамках выполнения соглашения № 05.595.21.0005 (уникальный идентификатор RFMEFI59519X0005). 


\section{Конфликт интересов}

У авторов отсутствует конфликт интересов.

\section{Список литературы}

[1] Zwinkels J.C., DeRose P.C., Leland J.E. // Experimental Methods in the Physical Sciences. 2014. V. 40. Chapter 7. P. 222. doi 10.1016/B978-0-12-386022-4.00007-8

[2] Velapoldi R.A., Mielenz K.D. A Fluorescence Standard Reference Material: Quinine Sulfate Dihydrate. U.S. Government Printing Office, Washington, DC, 1980. NBS Spec. Pub. 260-64.

[3] BAM Certified Reference Materials BAM F-001 B. F-002 B F-001 В. F-003 В F-001 В. F-004 В F-001 5 [Электронный peсурc] Режим доступа https://rr.bam.de/RRR/Content/EN /Downloads/RM-Certificates/RM-cert-optical-roperties /bam_f001b_f005b.pdf?_blob=publicationFile

[4] Reference Materials for Fluorescence Reference Spectrophotometry 6 BF Starna Scientific [Электронный ресурс] Режим доступа: http://www.starnacells.com/d_ref/d_fl/6BF.html

[5] DeRose P.C., Smith M.V., Anderson J.R., Kramer G.W. // J. Lumin. 2013. V. 141. P. 9. doi 10.1016/j.jlumin.2013.02.055

[6] DeRose P.C., Smith M.V., Mielenz K.D., Anderson J.R., Kramer G.W. // J. Lumin. 2011. V. 131. P. 2509. doi 10.1016/j.jlumin.2011.06.046

[7] DeRose P.C., Smith M.V., Mielenz K.D., Anderson J.R., Kramer G.W. // J. Lumin. 2011. V. 131. P. 1294. doi 10.1016/j.jlumin.2011.03.002

[8] DeRose P.C., Smith M.V., Mielenz K.D., Blackburn D.H., Kramer G.W. // J. Lumin. 2009. V. 129. P. 349. doi 10.1016/j.jlumin.2008.10.017

[9] DeRose P.C., Smith M.V., Mielenz K.D., Blackburn D.H., Kramer G.W. // J. Lumin. 2008. V. 128. P. 257. doi 10.1016/j.jlumin.2007.08, 003

[10] Hoffmann K., Spiels M., Bresmer W., Resch-Gernger U. // Anal. Chem. 2015. V. 87. N 14. P. 7204. doi 10.1021/acs.analchem.5b02209

[11] Lakowitcz J.R. Principles of Fluorescence Spectroscopy. Third edition. Springer, 2006. 954 р.; Лакович Джс. Основы флуоресцентной спектроскопии. М.: Мир, 1986. 496 с.

[12] ASTM-E 1840 Standard Guide for Raman Shift Standards for Spectrometers Calibration.

[13] Chouquette S.W., Etz E.S., Hurst W.S., Blackburn D.H., Leight S.D. // Applied Spectroscopy. 2007. V. 61. N 2. P. 117. 